\title{
LEY 20.418: FIJA NORMAS SOBRE INFORMACIÓN, ORIENTACIÓN Y PRESTACIONES EN MATERIA DE REGULACIÓN DE LA FERTILIDAD
}

\author{
http://www.leychile.cl/Navegar?idNorma = 1010482\&idParte =\&idVersion=2010-01-28
}

Teniendo presente que el $\mathrm{H}$. Congreso Nacional ha dado su aprobación al siguiente Proyecto de ley: Artículo 1‥ Toda persona tiene derecho a recibir educación, información y orientación en materia de regulación de la fertilidad, en forma clara, comprensible, completa y, en su caso, confidencial.

Dicha educación e información deberán entregarse por cualquier medio, de manera completa y sin sesgo, y abarcar todas las alternativas que cuenten con la debida autorización, y el grado y porcentaje de efectividad de cada una de ellas, para decidir sobre los métodos de regulación de la fertilidad y, especialmente, para prevenir el embarazo adolescente, las infecciones de transmisión sexual, y la violencia sexual y sus consecuencias, incluyendo las secundarias o no buscadas que dichos métodos puedan provocar en la persona que los utiliza y en sus hijos futuros o en actual gestación. El contenido y alcance de la información deberá considerar la edad y madurez psicológica de la persona a quien se entrega.

Este derecho comprende el de recibir libremente, de acuerdo a sus creencias o formación, orientaciones para la vida afectiva y sexual. Un reglamento, expedido a través del Ministerio de Salud, dispondrá el modo en que los órganos con competencia en la materia harán efectivo el ejercicio de este derecho.

Sin perjuicio de lo anterior, los establecimientos educacionales reconocidos por el Estado deberán incluir dentro del ciclo de Enseñanza Media un programa de educación sexual, el cual, según sus principios y valores, incluya contenidos que propendan a una sexualidad responsable e informe de manera completa sobre los diversos métodos anticonceptivos existentes y autorizados, de acuerdo al proyecto educativo, convicciones y creencias que adopte e imparta cada establecimiento educacional en conjunto con los centros de padres y apoderados.

Artículo $2^{\circ}$. Toda persona tiene derecho a elegir libremente, sin coacción de ninguna clase y de acuerdo a sus creencias o formación, los métodos de regulación de la fertilidad femenina y masculina, que cuenten con la debida autorización y, del mismo modo, acceder efectivamente a ellos, en la forma señalada en el artículo $4^{\circ}$.

Sin embargo, en aquellos casos en que el método anticonceptivo de emergencia sea solicitado por una persona menor de 14 años, el funcionario o facultativo que corresponda, sea del sistema público o privado de salud, procederá a la entrega de dicho medicamento, debiendo informar, posteriormente, al padre o madre de la menor o al adulto responsable que la menor señale.

Artículo $3^{\circ}$. Toda persona tiene derecho a la confidencialidad y privacidad sobre sus opciones y conductas sexuales, así como sobre los métodos y terapias que elija para la regulación o planificación de su vida sexual.

Artículo 4ํ․ Los órganos de la Administración del Estado con competencia en la materia, adoptarán las medidas apropiadas para garantizar el ejercicio de los derechos establecidos en esta ley. Para ello deberán elaborar planes que señalen las acciones respectivas.

Asimismo, los órganos de la Administración del Estado con competencia en la materia pondrán a disposición de la población los métodos anticonceptivos, que cuenten con la debida autorización, tanto hormonales como no hormonales, tales como los métodos anticonceptivos combinados de estrógeno y progestágeno, métodos anticonceptivos de progestágeno solo, los métodos anticonceptivos hormonales de emergencia y los métodos de anticoncepción no hormonal, naturales y artificiales. En todo caso, no se considerarán anticonceptivos, 
ni serán parte de la política pública en materia de regulación de la fertilidad, aquellos métodos cuyo objetivo o efecto directo sea provocar un aborto.

Artículo 5․ Si al momento de solicitarse la prescripción médica de un método anticonceptivo de emergencia o de solicitarse su entrega en el sistema público o privado de salud fuese posible presumir la existencia de un delito sexual en la persona del solicitante o para quien se solicita, el facultativo o funcionario que corresponda deberá poner los antecedentes a disposición del Ministerio Público, sin perjuicio de lo dispuesto en el artículo $198 \mathrm{del}$ Código Procesal Penal.

Habiéndose cumplido con lo establecido en el № 1 del Artículo 93 de la Constitución Política de la República y por cuanto he tenido a bien aprobarlo y sancionarlo; por tanto promúlguese y llévese a efecto como Ley de la República.

Santiago, 18 de enero de 2010. MICHELLE BACHELET JERIA, Presidenta de la República. Álvaro Erazo Latorre, Ministro de Salud. Mónica Jiménez de la Jara, Ministra de Educación. José Antonio Viera-Gallo Quesney, Ministro Secretario General de la Presidencia. Carmen Andrade Lara, Ministra Directora Servicio Nacional de la Mujer.

Lo que transcribo para su conocimiento. Saluda atentamente a Ud., Jeanette Vega Morales, Subsecretaria de Salud Pública.

\section{Crónica}

\section{ELECCIÓN DEL DIRECTORIO DE LA SOCIEDAD CHILENA DE OBSTETRICIA Y GINECOLOGÍA: PERÍODO 2010-201 1}

En una ceremonia encabezada por el actual presidente de la Sociedad Chilena de Obstetricia y Ginecología, Dr. Eugenio Suárez, el martes 22 de diciembre de 2009 , se realizó la elección de presidente de la SOCHOG para el período 2010- 2011. El presidente electo fue el Dr. Luis Martínez, quien actualmente se desempeña como vice-presidente de esta entidad científica, y asumirá el cargo a partir de abril de 2010.

De acuerdo a los estatutos de la Sociedad Chilena de Obstetricia y Ginecología, el Comité de Búsqueda de esta entidad se reunió en octubre de 2009, para proponer el listado de postulantes para ejercer los diferentes cargos del directorio para el periodo 2010-2011.
La propuesta de postulantes fue entregada durante una asamblea realizada en el auditorio de la Clínica Alemana Santiago, la cual fue aceptada por todos los miembros presentes en la ocasión.

De esta manera, fueron elegidos por aclamación los siguientes médicos con sus respectivos cargos: Presidente: Dr. Luis Martínez M.

Vice-presidente: Dr. Hernán Muñoz S.

Tesorero: Dr. Omar Nazzal N.

Secretario general: Dr. Mauricio Cuello F.

Secretarios de Actas: Drs. Carlos Schnapp Sch. y José Antonio Arraztoa V.

Directores: Drs. Álvaro Insunza F., Eduardo Faúndez P. y Dr. Fernando Abarzúa C. 